\title{
MEDIA LIVE STREAMING BERBASIS RASPBERRY PI PADA PERGURUAN TINGGI RAHARJA
}

\author{
Reynald Saevana Aria ${ }^{1}$ \\ Angi Nursetia Putra ${ }^{2}$ \\ Denny Andreansyah Putra ${ }^{3}$ \\ STMIK Raharja Jurusan Teknik Informatika ${ }^{1,2,3}$ \\ Jl. Jendral Sudirman No. 40, Modern Cikokol, Tangerang ${ }^{1,2,3}$ \\ Email : reynald@raharja.info ${ }^{1)}$, anggi.nursetia@raharja.info $^{21}$, denny.andreansyah@info ${ }^{31}$
}

\begin{abstract}
ABSTRAK
Perguruan Tinggi Raharja adalah kampus yang memfokuskan konsestrasi dalam bidang computer dan teknologi, namun dalam bidang penyampaikan informasi kepada mahasiswa masih kurang efektik karena masih menggunakan sebuah kertas atau poster yang di tempel di mading (Majalah Dinding) dan penampilannya pun tidak menarik mahasiswa untuk melihat dan menyimak informasi yang terdapat dikampus. Dibutuhkannya sebuah inovasi untuk memperbaharui metode penyampaikan informasi manual kedalam bentuk digital. Maka penulis mebuat alat media Broadcast informasi berbasis Raspberry Pi yang memanfaatkan fasilitas kampus seperti televisi untuk menampilkan beberapa informasi internal kampus dan sebagai wadah untuk menampilkan hasil karya Video Mahasiswa Mavib untuk ditampilkan kepada Pribadi Raharja.

Kata Kunci : Perguruan Tinggi Raharja, Raspberry Pi, Video, Teknologi
\end{abstract}

\begin{abstract}
Higher Education Prog is a university that focuses konsestrasi in the field of computer and technology, but in the field of penyampaikan information to students remains less efektik because they still use a paper or poster is attached to the wall magazine (Magazine Wall) and his appearance did not attract the students to see and listen information contained campus. The need for an innovation to renew methods penyampaikan user information into a digital form. The authors mebuat Broadcast media based information tool Raspberry Pi utilizing campus facilities like television to show some internal information campuses and as a forum to showcase the work of the Student Video Mavib to display to the Personal Prog.
\end{abstract}

Keywords: Higher Education Prog, Raspberry Pi, Video, Technology

\section{PENDAHULUAN}

Dalam kegiatan perkuliahan di Perguruan Tinggi Raharja masih adanya fasilitas yang tidak dipergunakan secara maksimal yaitu media televisi. Dengan berkembangnya Raspberry $P i$ akhir-akhir ini memicu berkembangnya inovasi baru yang memanfaatkan Raspberry Pi sebagai wadah untuk menampilkan hasil karya video dan film Mahasiswa MAVIB dalam bentuk media broadcast ke beberapa televisi yang ada dikampus.

Perkembangan teknologi komputer saat ini sangat pesat dengan pemanfaatan yang sangat luas dan hampir mencakup segala bidang. Salah satunya yang sedang menjadi topik hangat bagi kalangan IT adalah microcomputer Raspberry Pi. Raspberry Pi merupakan modul micro 
computer yang juga mempunyai input output digital port seperti pada board microcontroller. Kelebihan Raspberry Pi ini dari microcontroller lainnya yaitu mempunyai port koneksi untuk display berupa Televisi atau monitor PC serta port koneksi USB untuk keyboard dan mouse.

\section{RUMUSAN MASALAH}

Berdasarkan hasil wawancara pada Perguruan Tinggi Raharja, Sistem alat yang bekerja pada saat ini masih menggunakan manual. Manual di sini diartikan bahwa TV yang ada di perguruan tinggi raharja masih menggunakan satu persatu untuk memasukan karya mahasiswa yang untuk di tayangkan dan juga hanya di satu tempat mengendalikannya. Dapat diambil satu masalah yang mempengaruhi tersebut diantaranya akan menunggu tayangangan berikutnya, dan tidak bisa dikendalikan secara jauh, tidak dapat dikontrol dengan menggunakan hp android.

\section{LITERATUR RIVIEW}

1. Penelitian yang dilakukan oleh Muhamad Wahyudin dari Sekolah Tinggi Managemen Dan Ilmu Komputer (STMIK) RAHARJA, Pada laporan Kuliah Kerja Praktek tahun 2014 yang berjudul "PROTOTYPE ROBOT PEMOTONG RUMPUT TAMAN BERBASIS RASPBERRY Pi B+ MENGGUNAKAN WEB BROWSER PADA KANTOR KEPALA DESA PASIR GADUNG". Penelitian ini membahas tentang cara memotong rumput liat pada halaman kantor Kepala Desa Pasir Gadung menggunakan Raspberry Pi dengan web browser secara realtime.

2. Penelitian yang dilakukan oleh M.Rizky Noviadi dari Sekolah Tinggi Managemen Dan Ilmu Komputer (STMIK) RAHARJA, Pada laporan Skripsi tahun 2013 yang berjudul "MEDIA PENYIMPANAN DAN PEMBELANJAAN BERBASIS CLOUD COMPUTING MENGGUNAKAN RASPBERRY Pi PADA LINGKUNGAN RT". Penelitian ini membahas tentang bagaimana menyimpan data berbentuk softcopy dengan lebih efektif dan efisien.

3. Penelitian yang dilakukan oleh Riadoh Sunandariyah dari Akademi Manajemen Informatika dan Komputer (AMIK) RAHARJA pada laporang Tugas Akhir (TA) tahun 2013 yang berjudul "IMPLEMENTASI MEDIA DENGAN MENGGUNAKAN OPEN SOURCE RED5 DAN LINUX PADA PT CAHAYA TELEVISI INDONESIA". Penelitian ini mebahas tentang cara streaming audio,video, shared object,recorded cliend streaming menggunakan Red5. Red5 adalah teknologi Open Source yang berperan sebagai media server.

4. Penelitian yang dilakukan oleh Lusyani Sunarya dari STMIK Perguruan Tinggi Raharja pada laporan jurnal yang berjudul "DESIGN VIDEO PROFILE BASED MULTIMEDIA AUDIO VISUAL BROADCASTING AS A MEDIA PROMOTION". Penelitian ini membahas bagaimana merancang media berbasis audio visual agar dapat menjadi daya tarik yang efektif,terutama dalam penyampaian informasi dan promosi mengenai hal-hal yang berkaitan dengan keseluruhan isi.

5. Penelitian Jurnal Ilmiah yang dilakukan oleh Untung Rahardja, Muhamad Yusup, dan Fitriani dari Perguruan Tinggi Raharja pada tahun 2013 berjudul "Penerapan Proses 
Belajar Melalui iLearning Video Tutorial (iVit) Pada Perguruan Tinggi" menjelaskan tentang cara yang efektif untuk belajar melalui video pada seluruh civitas akademika. iLearning Aplikasi Video Tutorial (iVit) yang digunakan di iPad adalah aplikasi yang efektif dan praktis untuk memaksimalkan proses belajar tanpa harus langsung bertatap muka, sehingga pengguna dapat mengulangi proses belajar dimana saja. Penerapan proses pembelajaran dengan aplikasi iVit, diharapkan dapat meningkatkan kulaitas pembelajaran di pendidikan tinggi. Dari lima literature review yang ada, telah banyak penelitian mengenai multimedia, media broadcast, data digital serta pembahasannya perihal metode pengembangan microcomputer Raspberry P $i$.

\section{PEMECAHAN MASALAH}

Setelah mengamati dan meneliti dari beberapa permasalahan yang terjadi pada sistem yang berjalan, terdapat beberapa alternatif pemecahan dari permasalahan yang dihadapi yaitu, dengan menggunakan alat Raspberry Pi. Bisa dikendalikan dimana saja, bisa menggunakan $\mathrm{hp}$ android untuk mengendalikan live straiming.

\section{IMPLEMENTASI}

OSMC (Open Source Media Center) adalah media player gratis dan open source berbasis Linux. Didirikan pada tahun 2014, OSMC memungkinkan Anda bermain kembali media dari jaringan, penyimpanan terpasang lokal dan internet. OSMC adalah pusat media terkemuka dalam hal set fitur dan masyarakat dan didasarkan pada Kodi proyek.

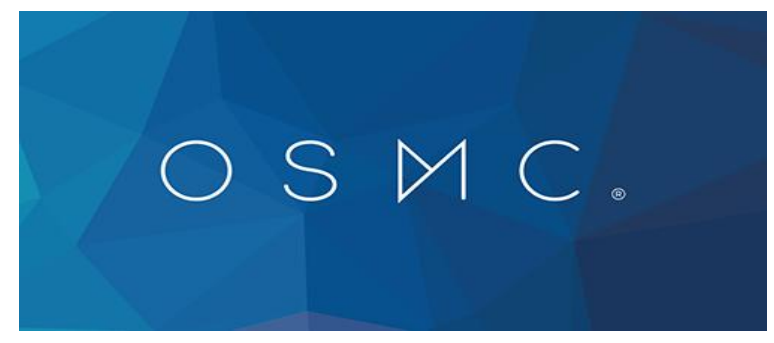

Gambar 1. OSMC (Operating System Media Center)

Sebelum memilih opsi intall on an SD Card, masukkan SD Card dan hubungkan kelaptop menggunakan Adaptor atau Cardreader. Pastikan SD Card tersebut dalam keadaan kosong, disarankan sebelum melakukan penginstallan SD Card terlebih dahulu di Format agar memastikan SD Card tersebut dalam keadaan kosong tidak terisi file apapun. Diharuskan SD Card tersebut memiliki kapasitas minimal 4GB dan mempunyai class 10 agar saat melakukan penginstallan tidak mengalami error. Jika SD Card sudah terhubung ke laptop, klik opsi install on an SD Card.

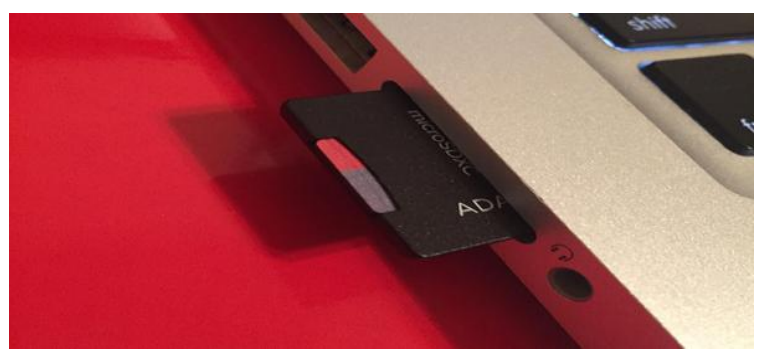

Gambar 2. SD Card 
Pasang perangkat keras pada Raspberry Pi seperti keyboard, mouse, kabel HDMI, power supply $5 \mathrm{v}$ (Charger Adaptor).

Jika perangkat keras sudah terpasang semua pada Raspberry Pi, maka tahap selanjutnya yaitu menghubungkan kabel HDMI dari Raspberry ke Televisi dan juga hubungkan Powersupply Raspberry ke listrik. Maka secara otomatis Raspberry akan melakukan booting interface OSMC.

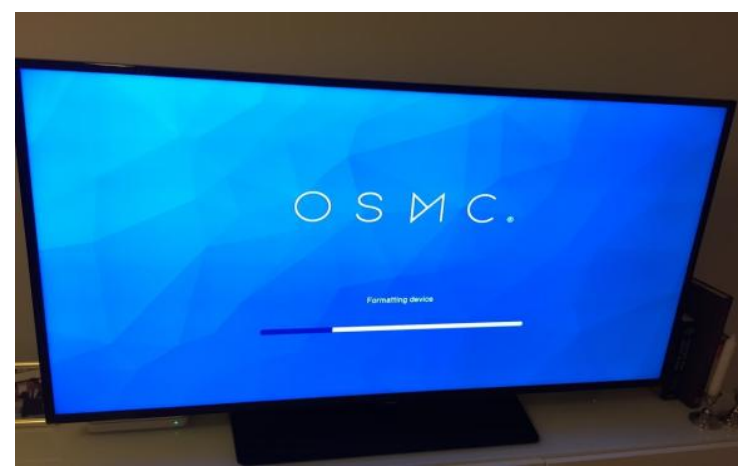

Gambar 3. Booting OSMC

Setelah proses booting selesai maka akan muncul tampilan interface OSMC yang bernama Kodi. Terdapat beberapa opsi seperti Video, Musik, Gambar, Setting. Pilih opsi video lalu masuk ke penyimpanan dan putar video yang ingin ditampilkan pada Televisi tersebut.

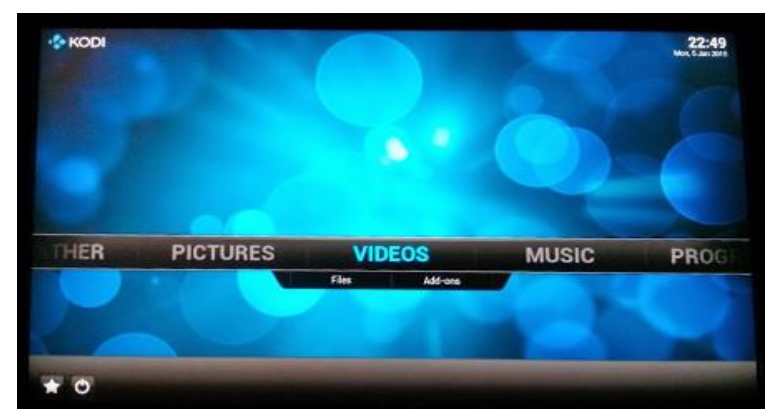

Gambar 4. Interface OSMC

Sama seperti cara instalasi melalui media online tahap pertama buka alamat https://osmc.tv, lalu klik download dan pilih menu gambar disk.

Setelah dipilih maka akan muncul beberapa versi OSMC untuk Raspberry Pi 1,2,3 dan Apple TV. Pilih OSMC versi Raspberry Pi 2/3 dan unduh versi release terbaru.
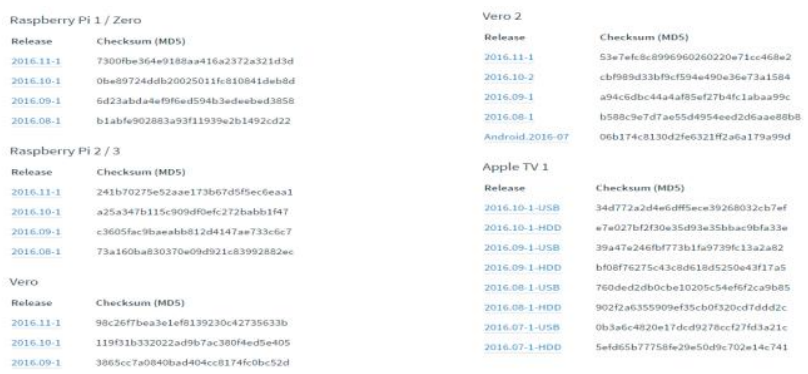

Gambar 5. versi OSMC untuk Raspberry Pi 
Pada pilihan ini dikhususkan untuk menceklis opsi use a local build on my computer untuk mengambil file disc image yang sebelumnya telah diunduh. Setelah di ceklis maka akan muncul jendela untuk mencari dimana file Discimage tersebut.

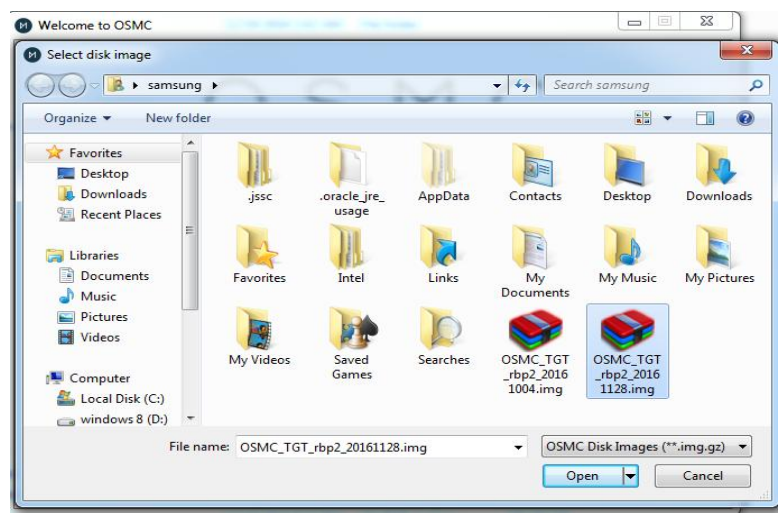

Gambar 6. menceklis opsi use a local build on my computer

Flow chart sistem kerja Media Live Streaming Berbasis Raspberry Pi.

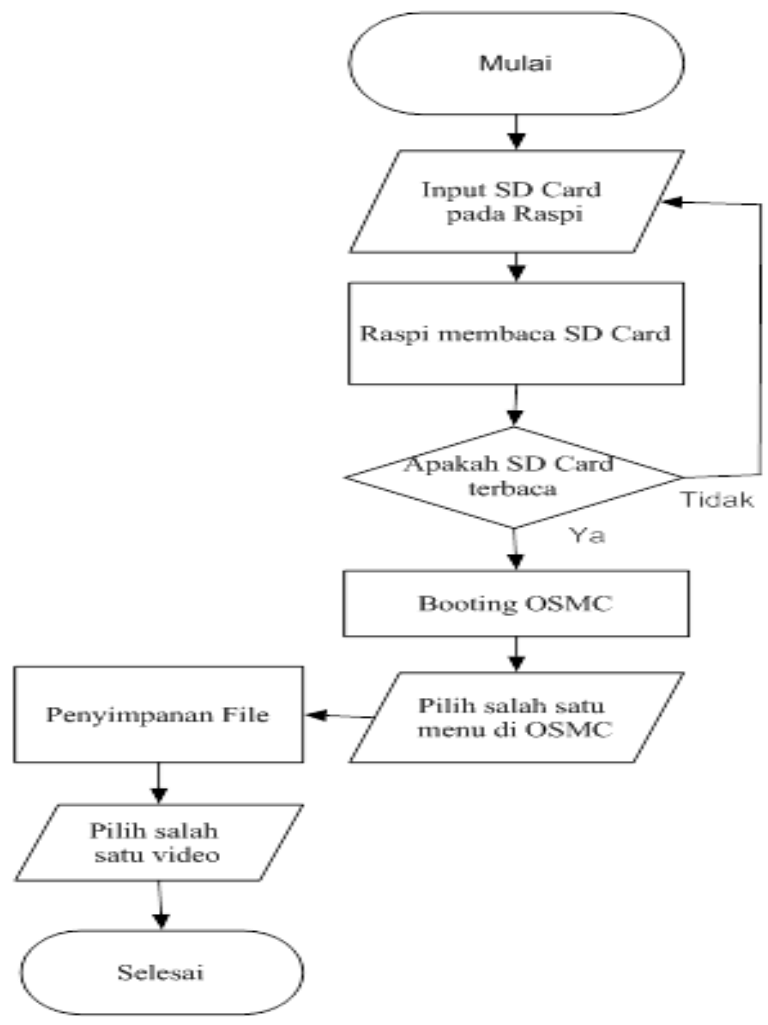

Gambar 7. Flowchart yang diusulkan

\section{KESIMPULAN}

Media Broadcast Video Streaming berbasis Raspberry Pi ini dibuat dan diharapkan dapat memudahkan Pribadi Raharja untuk mendapatkan suatu informasi yang terdapat dikampus dalam bentuk media digital. Dapat juga sebagai tempat menyalurkan beberapa video film hasil kreatifitas Mahasiswa Raharja yang bisa ditampilkan kepada para Pribadi Raharja agar dapat menjadi tonton menarik yang tersedia dikampus. 


\section{DAFTAR PUSTAKA}

[1] Amin. Zaenal, dan Santoso. Yudi. 2012. Pemodelan Sistem Informasi Persediaan Barang Pada PT. Nutech Pundi Arta. Jakarta: Universitas Budi Luhur.

[2] Budiman, Agustiar. 2012. Pengujian Perangkat Lunak denganMetode Black Box Pada Proses Pra Registrasi UserVia Website. Makalah, halaman: 4.

[3] Darmawan, Deni. 2012. Pendidikan Teknologi Informasi dan Komunikasi. Bandung: PT Remaja Rosdakarya.

[4] Hartono, Bambang. 2013. Sistem Informasi Manajemen Berbasis Komputer. Jakarta: Rineka Cipta.

[5] Jogiyanto Bukunya Yakub. 2012. "Pengantar Sistem Informasi”.Graha Ilmu.

[6] McLeod, Reymond dan George P. Schell. "Sistem Informasi Manajemen". Edisi Ke-10. Jakarta: Salemba Empat.

[7] Novialdi, M.Rizkya. 2013. "MEDIA PENYIMPANAN DAN PEMBELANJAAN BERBASIS CLOUD COMPUTING MENGGUNAKAN RASPBERRY Pi PADA LINGKUNGAN RT". Perguruan Tinggi Raharja. Tangerang.

[8] Rahardja, Untung 2013. Vol.6 No.2. "Penerapan Proses Belajar Melalui iLearning Video Tutorial (iVit) Pada Perguruan Tinggi”. CCIT Journal. Perguruan Tinggi Raharja. Tangerang.

[9] Saputra, Agus, Ridho Taufiq Subagio, dan Saluky. 2012. Membangun Aplikasi ELibrary untuk Panduan Skripsi. Jakarta: PT Elex Media Komputindo.

[10] Sastra Hadiprawira, Arie. 2014. "Pembangunan Aplikasi Game Cerita Rakyat Fabel "Skripsi.Fakultas Teknik dan Ilmu Komputer,Universitas Komputer Indonesia. Bandung.

[11] Siddiq, Asep Jafar 2012. REKASA PERANGKAT LUNAK. Yogyakarta: C.V ANDI OFFSET

[12] Subrata, Karno. 2015. “Analisis dan Perancangan Sistem”. Flowchart Jurnal.

[13] Sunandariyah, Riadoh 2013. "IMPLEMENTASI MEDIA DENGAN MENGGUNAKAN OPEN SOURCE RED5 DAN LINUX PADA PT CAHAYA TELEVISI INDONESIA”. Perguruan Tinggi Raharja. Tangerang. 